\title{
Ética en las publicaciones médicas
}

\author{
Ethics in medical publications
}

\author{
Guillermo Bannura C. ${ }^{1}$
}

Las publicaciones científicas en el área médica superan el millón por año y en el área quirúrgica aproximadamente el 14\% tiene algún sesgo de mala conducta que vulnera las normas éticas o simplemente representa un fraude. A pesar de los intentos a nivel mundial de minimizar los problemas éticos y otras malas conductas asociadas a las publicaciones médicas, el plagio y la duplicación han aumentado en forma exponencial. Estas prácticas vulneran la credibilidad de una revista y daña los principios éticos que debieran ser el norte de una publicación científica.

Distintas organizaciones y comités que se han consolidado a través de los años señalan la necesidad de aunar los esfuerzos de los autores, los revisores y los editores para minimizar este flagelo, lo que ciertamente no es fácil. Entre otras, destacan la Asociación Mundial de Editores Médicos (WAME por sus siglas en inglés) ${ }^{1}$, el Comité Internacional de Editores de Revistas Médicas (ICMJE)² y el Comité de Ética para Publicaciones (COPE) ${ }^{3}$.

El COPE, que se inició en 1997 en UK con un pequeño grupo de editores preocupados del tema, actualmente supera los 11.000 miembros y en la base de datos del COPE se han presentado más de 500 casos de mala conducta los que se discuten en un Foro ${ }^{4}$. Esto ha enriquecido el manejo del tema, proporcionando mucha información relevante a los autores, revisores y editores, los que en definitiva tienen que decidir en casos grises. COPE no investiga una mala conducta en la investigación o una publicación específica, sino que orienta y opina a la luz de la experiencia acumulada sobre algún caso dudoso presentado por los editores miembros.

A pesar de que la Revista Chilena de Cirugía ha dedicado dos editoriales sobre el tema ${ }^{5,6}$, la relevancia del mismo hace necesario destacar algunos aspectos que pueden ser confusos o discutibles. El trabajo clásico de De Perrot ${ }^{7}$ de Ginebra sobre los quistes mesentéricos fue copiado y publicado en una revista mejicana cambiando solo el nombre de los autores y el centro de origen, lo que motivó un reclamo del autor de este editorial y una sanción verbal a los autores de parte de la revista afectada. Esto no admite duda: se trata de un plagio, robo o fraude intelectual desde cualquier ángulo que se le mire. El autoplagio y el reciclamiento de un texto ocurren cuando se publica el mismo trabajo en diferentes revistas con títulos distintos, utilizar en un nuevo estudio material ya publicado y presentar un trabajo previamente presentado como original. En el análisis de los primeros 16 años de COPE, este fue un problema iterativo ${ }^{8}$. La duplicación y la publicación salami (parcial) admite algunas zonas grises y la recomendación considera que cada revista aclare exactamente lo que considera una duplicación en las instrucciones a los autores. De esta forma, se confirma lo señalado en nuestra Revista ${ }^{5,6}$ que los abstracts, los posters, los resultados presentados a los participantes de una investigación, y las bases de datos no son considerados como una publicación previa por la Blackwell Publishing ${ }^{9}$. Respecto de la re-publicación de un artículo traducido derivado de una publicación original escrito en un idioma diferente no se considera una publicación redundante, siempre que se asegure el permiso de la revista primaria y se haga la cita del artículo original ${ }^{9}$. Esto tiene importancia para nuestra Revista, toda vez que un artículo de peso podría ser publicado en una revista internacional de alto impacto, por ejemplo, en inglés, y luego republicarla en español o viceversa, tomando los resguardos señalados. Las revistas más importantes del área quirúrgica han mantenido este criterio, lo que está detallado en una publicación previa $^{5}$. Republicar en el mismo idioma del trabajo original es más difícil de justificar, especialmente si el artículo es accesible por vía electrónica.

En conclusión, aunque sea lamentable, las transgresiones a la ética de las publicaciones en el área de la medicina es un hecho indesmentible que todos debemos combatir, cooperando con los editores y los revisores de nuestra Revista. Los casos dudosos pueden ser consultados a COPE que brinda una asesoría inestimable sobre el caso específico y, especialmente, orienta en el manejo de los casos que presentan conductas reñidas con la ética médica.
${ }^{1}$ Ex Presidente Sociedad de Cirujanos de Chile.

Correspondencia a: gbannura@gtdmail.com 


\section{EDITORIAL}

\section{Referencias}

1. World Association of Medical Editors. Recommendations on Publication Ethics Policies for Medical Journals (Internet) 2004. Disponible en http://www. wame.org/about/recommendations-onpublication-ethics-policie.

2. ICMJE. Recommendations for the Conduct. Reporting, Editing and Publication of Scholarly Work in Medical Journals. (Internet) 2016. Disponible en http://citeseerx.ist.psu.edu/viewdoc/ download.
3. Committee on PUblication Ethics. About COPE (Internet). 20187.

Disponible en http://publicationethics. org/about.

4. Pierson CA. Avoiding ethics pitfalls in publishing: a perspective from COPE. Oral Disease 2017;23:416-9. Doi:10.1111/ odi.12539.

5. Bannura G. Duplicación en la presentación y publicación de un artículo médico. Rev Chil Cir. 2006;58:75-6.

6. Bannura G. Publicación duplicada y autoplagio en publicaciones médicas. Rev Chil Cir. 2017;69:1-2.
7. de Perrot M, Bründler MA, Tötsch M, Mentha G, Morel P. Mesenteric cysts. Toward less confusion? Dig Di 2000; 17:323-8.

8. Hames I, on behalf of COPE (2013). COPE Ethical Guidelines for Peer Reviewers. Available at http:// publicationethics.org/resources/guidelines.

9. Graf C, Wager E, Bowman A, Fiack S, Scott-Lichter D, Robinson A. Best practice guidelines on publication ethics: a publisher's perspective. Int J Clin Pract. 2007;61:126. 